\title{
I Learn Korean My Way: A Case Study
}

\author{
Katrina Mae L. Allado ${ }^{1}$, Aprian Joyce B. Peñol ${ }^{2}$, Donna O. Bachiller ${ }^{3}$ \\ Bachelor of Arts in English, UM - Matina Campus, Davao City, Philippines \\ Ikatrinamaeallado@gmail.comm, ${ }^{2}$ aprian30@yahoo.com, 33donna_102995@yahoo.com
}

\author{
Mary Ann E. Tarusan, EdD, PhD \\ Language Professor, UM - Matina Campus, Davao City, Philippines
}

\begin{abstract}
This qualitative single case study explored the experiences of a self-taught Korean language learner. The researchers sought to explore the tools she used, the strategies she employed and triumphs and difficulties that the participant experienced in learning the Korean language. There were five tools utilized in order to gather the relevant data for the study. These includes an in-depth interview, direct observation, participant- observation and gathering of relevant documents and physical artifacts from the participant. The results revealed that the main tools used by the participant were books and instructional videos, most of the strategies she used were metacognitive and she experienced difficulties in the unique feature of the Korean language. However, she finds Korean language learning very enjoyable and she enjoys Korean culture as well.
\end{abstract}

Keywords: Foreign language learning, learning Korean, self- teaching.

\section{INTRODUCTION}

In today's setting where access to second language learning is easy and varied, one does not have to meet a native speaker in order to learn the language. Countries have included foreign language learning in their schools' curriculum. Language centers for different languages are also thriving in the business industry. But for those who do not have educational access, independent learning is not impossible.

White (2008) postulated in her study that principles underlying independent language learning includes adjusting or extending learner choice, focusing on the needs of individual learners, not the interests of a teacher or an institution. Learners in independent learning environments learn without the presence of a teacher thus requiring them to be responsible for their learning (Hurd\& Lewis, 2008). This situation has resulted to developing various means in raising learners' awareness and knowledge of themselves, their learning needs and preferences, their beliefs and motivation and the strategies they use to develop target language competence. (White, 2008).

In the Philippines, second language learning is common. Aside from Filipino, English is also considered as an official language. Chavez (2014) believed that the Filipinos are able to master English language due to sustaining the interest and dedicating resources in learning the language after the American colonizers left. Today, another interest to learn a foreign language seems to grow especially among Filipino youth as they are swept by Hallyu or the "Korean Wave" (Zhou, 2014). Korean dramas and Korean music became a trend in the Philippines. Many young Filipinos are now interested in learning Hangul or Korean language (Perez, 2014).

Locally, Koreans also impacted lives of Davaoeños. There were 2,675 Koreans living in the Davao Region in 2011, according to Ministry of Foreign Affairs and Trade, Korea statistics. Korean have also put up some investments in the city (Francisco, 2002). The persistent integration of Korea's culture through their dramas, music and constituents living in the nation clearly made the Korean language an interesting language to learn. The researchers were able meet this person who has a great interest for Korean culture and utterly desired to learn their language that she was able to learn it without formal schooling. This study explores the tools she used, the strategies she employed and her experiences in her pursuit of learning the Korean language. 


\subsection{Statement of the Problem}

This study aims to determine the tools and strategies used by the Filipino language learner who learned the Korean language without formal instruction and the aid of a qualified instructor and her experiences.

Specifically, this study sought to answer the following questions:

1. How did the Filipino language learner acquired the Korean language independently?

2. What strategies are used by the participant in acquiring Korean language?

3. What are the triumphs and difficulties experienced by the participant in learning Korean language?

\subsection{Theoretical Lens}

The theories in which the study was anchored were the theories of cognitive micro- processes of attention and Oxford's Taxonomy of Learning Strategies. The term micro- processes is used to refer to the specific mental operations involved in different stages of acquisition (Ellis, 2008). On the other hand, Oxford's (1990) taxonomy of foreign language learning strategies is one of the most extensively utilized classifications in education and research on language learning.

Noticing Hypothesis claims that the concept of attention is necessary in order to understand virtually every aspect of second language acquisition including the development of inter languages over time, variation within inter language at particular points in time, the development of second language fluency, the role of individual differences such as motivation, aptitude, and learning strategies in second language learning, and the ways in which negotiation for meaning, and all forms of instruction contribute to language learning (Schimdt, 2001). In other words it asserted that learning a second language entails attended learning. The hypothesis identified the key attentional process as that of 'noticing' (Schimdt, 2001).

Conversely, Theory of Attention presented a different view (Tomlin and Villa, 1994). It differentiated three kind of attentional processes: (1) alertness, which involves a general readiness to deal with incoming stimuli and is closely related to the learner's affective or motivational state, (2) orientation which entails the aligning of attention on some specific type or class of sensory information at the expense of others and (3) detection, when the cognitive registration of a sensory takes place. It is during the last of these processes that particular exemplars of language are registered in memory (Tomlin and Villa, 1994).

On the other hand, Input Processing Theory is based on the standard information processing viewpoint (Van Patten, 1996). Working memory is limited in capacity making it difficult for learners to attend concurrently to different stimuli in the input. He identified 'detection' as the key attentional process, noting that detecting one bit of information can interfere with the detection of others by consuming available resources in working memory. Thus, for this theory, the main issue is how learners allocate attentional resources during online processing and in particular, what causes them to detect certain stimuli in the input and not others (Van Patten, 1996).

Lastly, Multiple- Resource Model surveys work on attention (Robinson, 2003). In this work, it divided three senses of attention: (1) attention as selection (corresponding to the first stage in an information-processing model where input is perceived), (2) attention as capacity (corresponding to the central control and decision making stage), and (3) attention as effort (referring to the sustained attention involved in response execution and monitoring). (Robinson, 2003).

This study is also anchored in Oxford's Taxonomy of strategies. Language learning strategies focus on how learners cope with language learning more easily and more effectively and introduce a useful help for them (Kozmonova, 2008). As for definitions of language learning strategies in the area of linguistics, it was specified in the following way: "Learning strategies are the particular approaches or techniques that learners employ to try to learn a second language" (Ellis, 1997).

The aim of language learning strategies is oriented towards the development of communicative competence (Oxford, 1990). The language learning strategies divided into two main classes: direct and indirect, which are further subdivided into 6 groups. In Oxford's system, metacognitive strategies help learners to regulate their learning. Affective strategies are concerned with the learner's emotional requirements such as confidence, while social strategies lead to increased interaction with the target 
language. Cognitive strategies are the mental strategies learners use to make sense of their learning, memory strategies are those used for storage of information, and compensation strategies help learners to overcome knowledge gaps to continue the communication.

\section{METHOD}

\subsection{Research Design}

This study used the qualitative- single case study method. There were no other cases available for replication, so the researchers adopted the single-case design. The researchers used the method to have an insight to the experience of the participant in her quest to learn Korean as second language. The researchers selected a qualitative method in order to assess aspects and objectivity that might be lost if quantitative or experimental strategies will be applied. San Jose (2012) stated that qualitative is more dynamic compared to the designed format of the quantitative method. In addition, Robson (2011) characterizes qualitative research as flexible rather than rigid, and inductive rather than ensuing a firm order or consequent from a preliminary choice.

\subsection{Research Participant}

The study at hand discovered the different tools used by the participant in her quest to learn Korean as a second language; the strategies she used in order for her to learn it and her experiences in learning the language. To be specific, the researchers inquired about the triumphs and difficulties she encountered during the learning process.

The participant was born on Davao City and was intensely interested in learning the Korean language as well as the Korean lifestyle and culture. In her accounts, she had been studying the Korean language for five years now using only instructional videos, reference books, and interaction from Korean friends in social networking sites. She is able read Korean characters and can watch Korean drama series without the aid of subtitles.

\subsection{Research Instrument}

The sources of data in this study were interviews, participant-observation, direct observation, documents and physical artifacts. These sources of data were utilized as a way of collecting data from the only participant involved in the study. The following proceedings explain the nature of what and how the specific datum was gathered.

\subsubsection{Interview}

The researchers conducted an in-depth interview with the participant to collect relevant information which can shed light on the information which the study sought to answer. The interview was anchored to three research questions. There were four main questions with three probe questions each to extract more information from the participant.

The research questions focused on the how the Korean language was acquired by the participant without formal instruction, what strategies the participant used in order to learn the target language, and the experiences of the participant throughout the learning process. Before the interview, the researchers produced interview guide questions to lead the researchers in the conversation with the participant. The interview guide questions that were validated by three experts on the research field.

The interview was audio-recorded and written with the permission of the participant. It was then transcribed selectively, verified by the participant and analyzed systematically.

\subsubsection{Participant-Observation}

In participant-observation, the researcher actually takes on the role being studied (Yin, 2012). This was materialized in the study by watching the instructional video that the participant used to learn the language. The participant was also present in the event and shared her insights about the videos. The videos were from the Korean cable channel Arirang. Let's Speak Korean" is a Korean conversation program.

A highlight of "2008 Let's Speak Korean" is the introduction of sitcoms, which means viewers can enjoy the process of improving their Korean conversation skills. The sitcoms aim to teach viewers "lively Korean" in a natural way with situational expressions and a comical format. Korean lectures are included. This means viewers can learn Korean and have fun in the process. (http://www.arirang. co.kr/) 


\subsubsection{Direct Observation}

Direct observation take shape of utilizing one's five senses, taking notes, and finally producing a narrative based on what you might have seen, heard, or otherwise sensed (Yin, 2012). The researchers utilized direct observation in documenting the conversation between the participant and a native Korean speaker. This occurred at the fifth meeting of the researchers and the participant. The researchers, with the help of their adviser, set up an informal meeting of the participant and the Korean native language speaker. The Korean was a 3rd year student studying at the University of Mindanao. At the first part of the conversation, the participant asked the Korean native speaker in Korean language. The Korean native speaker answered in English. At the latter part of the conversation, it was the Korean native speaker's turn to ask our participant and he used Korean language. The participant too, answered in the same language. At the end of the conversation, the Korean native speaker shared his comments about the participant's skill in Korean language.

\subsubsection{Documents}

The researchers also gained access to the participant's personal documents such as the participant's notebook where she used in learning the Korean language and a letter she received from a Korean friend. The first entry in the notebook she used was dated December 24, 2012. It contains notes from the one hundred episodes of the series 'Let's Speak Korean' from the Arirang channel. The participant listed the Korean characters and its corresponding English translation.

\subsubsection{Physical Artifacts}

The researchers were able to get a hold of the books and other tools that the participant used to learn the Korean language. These includes English-Korean-Filipino Dictionary, postcards from Seoul, a pamphlet entitled Essential Korean Phrase book, Busan Korea postcards, Korean Dictionary for Elementary Students, Korean Phrasebook \& Dictionary, Tuttle Learner's Korean-English Dictionary, Primary Korean Lesson Book, Korean guidebook, 50 years of Dynasty Korean History Book, Korean Dictionary, Korea Must-See-Routes travel guide and Korean maps. The participant claimed that all of these artifacts helped her in learning the Korean language.

\subsection{Data Gathering}

The researchers used in-depth interview as the major gathering tool in this research aside from observation. The interview made use of the open-ended type of interview question to provoke particular experiences of the participant.

Moreover, the construction of the interview guide questions is in line with the research question of the study. It concentrated on the language learning experiences of the participant throughout the learning process. It also includes inquiry about the primary tools used by the participant in learning the language and the strategies she used in order to learn it. The interview guide questions served as a reference for the discussion with the participant. The purpose of it is to draw out information about Korean language learning process.

Furthermore, three expert validators authorized the interview guide questions before it was used in the administration of the study to ensure that the questions would not be offensive to the participant but rather evoke data that were in-line with the interest of the study.

The researchers first sought a consent of the participant to inform her about the purpose of the study. They provided a consent letter to the participant to confirm her engagement of the study.

The gathering of information involved five meet-ups that include an observation of the conversation between the participant and a native Korean speaker and a formal interview. During the interview, the researchers clarified what she did not understood from the research questions. Moreover, aside from the probe questions, the researcher also asked more questions that is still in line with the study in order to extract more information from the participant.

In the second meeting, the researchers clarified her answers that were not really clear in the recordings. The participant also showed the notebook she used in learning Korean. In the event, the researchers handed to the participant the consent letter for her to sign. In the third meeting, the researchers and the participant talked further about her experiences in learning the Korean language and the researchers also asked her of what really prompted her to learn the language. The participant as well further shared what was written in her notebook. In the event, the researchers watched the 
YouTube videos the participant used during her study of the language. In the fourth meeting, the participant showed the researchers the books and other references that she utilized during her learning of the Korean language.

In the last meeting, the researchers asked the consent of a native Korean speaker to have a conversation with the participant to for the researchers to see how well the participant can communicate in Korean language. The conversation lasted for six minutes were the participant and the Korean native speaker had a spontaneous exchange of random questions and answers. At the end, we asked the native Korean speaker to evaluate our participant's skill in communicating using the Korean language. Finally, the researchers expressed their deep gratitude to the Korean native speaker especially to the participant for her enthusiastic participation in the study.

\subsection{Trustworthiness}

Guba and Lincoln (1981), Krefting (1991) and Crotty (1998) state that there are four strategies to employ trustworthiness of a research; these are credibility, transferability, dependability and confirmability. Credibility refers to the reliability and dependable analyses of the data collected, dependability is the degree to which the results of the study can be simulated, confirmability denotes how well the results are reinforced by the information gathered and finally, transferability is concerned with the relevance of results outside the limit of the research.

Credibility in a qualitative research is the amount to which the information collected and information analyses are reliable and trustworthy. Lincoln and Guba (1985) asserted that credibility assesses the outcomes from the survey if it holds a "credible" explanation from the original data obtained from the participants. Credibility was materialized in this study by making sure that the recorded and transcribed interview was shown to the participant for her authentication.

Meanwhile, Merriam (1998) viewed dependability as the amount to which the results of the research can be replicated using comparable subjects and context. Therefore, dependability highlights the logicality of their research findings. To cater the matter of dependability, the research questions of this study were certified and authenticated by three expert validators before it was administered to guarantee the results of the research. Furthermore, the transcribed interview was authenticated by the participant.

On the other hand, conformability measures how well the outcomes are reinforced by the data collection prepared by the researchers (Fenton \&Mazulewiks, 2008). Thus, the researchers rendered an audit trail to demonstrate conformability in the study. Audit trail served as a reference index for the transcripts of the interviews (San Jose, 2012). The various procedures conformed from the beginning up to the analysis and reporting of the results followed in this research are made available. The study also included the reference codes of the participant's answers.

Lastly, transferability is concerned whether the findings reported are relevant beyond the limitations of the research. Merriam (1998) asserts that transferability "is concerned with the extent to which the findings of one study can be applied to other situations". Transferability was concretized in this study by showing comprehensive information of the settings and other information about the participant of the study discussed in the research participant section. Furthermore, the outcome of this study could also be used by other researchers for any further research. Additionally, the researchers included some of the documents that were used to gather data from the participant in the study. The researchers made it certain that the data would be accessible upon request by other researchers.

\subsection{Scope and Limitation}

The study is conducted with accompanying limitations that provides the clear focus of the study. The focus of this study is to determine the tools, strategies, and experiences of a particular Korean language learner who have not undergone any formal instruction in learning the language. The researchers were able to get to know the participant by an acquaintance. The researchers sought her consent and she agreed to be the subject of our study. Since there are no other cases available for replication, the researcher adopted the single-case design.

The only participant in the study is a female 21 year-old Visayan speaker who studied Korean through online videos and reference books. In her account, she have studied the Korean language intensively for five years using her tools. Having no other known person to have the same experience as our participant, the researchers chose to delimit the study to only one participant. 
This study used the qualitative case study as the research design. The data were collected through an in-depth interview of the participant aided by a tape recorder and observations. Moreover, the analysis of the data only covered the tools and strategies used by the participant in learning the language and her experiences.

\section{RESUlts AND DiscusSiON}

\subsection{Tools used to Learn the Language}

It was discovered through the investigation that the participant used books and the 130 episodes from the YouTube in order to learn the language. The participant finds the YouTube as more effective because it is already complete. It proves that video clips can function numerous drives; they can aid language learner gather the main ideas of communicative measures, grasp the meaning of unknown words, establish data extracted from linguistic input, and construct plans for the situational context (Kitajima and Lyman-Hager, 2013). Video can also serve as an innovative planner for language learning activities (Ausubel, 1968; Altman, 1987; Joiner, 1986; O’Maggio-Hadley, 1993).

The videos teach reading, listening and pronunciation. When the researchers viewed the video she used, it was indeed informative and comprehensive. The video was entitled 'Let's Speak Korean' from Arirang channel. In the video, there is a host, a traditional Korean teacher and a foreigner student who wants to learn the Korean language. They use English as a medium to teach the Korean language. The video includes situational contexts of where to use the expressions they teach. It also includes subtitles in Korean alphabet while the hosts say its meaning in English. They emphasize respect as they teach the foreigner the expressions to use in formal settings like when talking to a teacher. At the end of the video, the foreigner student is given a quiz to see if he learned what was taught. In this section, Caring relates that it helped her because like the foreign student, she answers the questions and checks if she also got the lesson right. Furthermore, the video does not only teaches Korean language, it also incorporates cultural facts about Korea.

Contrary to the videos, she stated that the least helpful tool are the books because there are misspelled words in the books. When you translate it, the sound is wrong. In YouTube, they teach by sound because the Korean language is more by phonemes. Indeed, most learners notice the fact that any other word could be incorporated into Korean language with only minor changes to the sound (Lee, 2011). Furthermore, the concept of multiple pools of attentional resources allocation does not support books as a tool to increase learner's performance. Robinson (1995) introduces Wicken's concept of multiple pools of attentional resources allocation. According to this view, attentional resource allocation consists of intersecting but independent pools of cognitive processing procedures such as various cognitive activities, analog/spatial activities versus linguistic activities, auditory versus visual perceptual activities, and vocal versus manual responses. This view of information processing proposes that tasks which require the same pool of attentional resources increases learning demands and slows learner performance. Books require only a single pool of attention which is visual perception. Thus, according to this view, books cannot be an effective tool to improve a learner's performance. On the other hand, tasks which require the simultaneous use of different pools of attentional resources such as videos, enable learners to integrate these resources and allow them to process information more efficiently.

Additionally, she thinks that it is helpful to encounter a native speaker in order to learn a second language. She believes it is important to meet a native Korean speaker because it is more needed and it will enhance one to [know] what is right because it is more accurate than what is in TV or YouTube. Sometimes they upload pranks. She affirmed and added that if you can communicate with them every day the Korean native speaker can provide another word. Her view agrees with Long's (1996) Interaction Hypothesis in which it believes that conversational interaction enhances second language acquisition. Accordingly, negotiation of meaning which triggers interactional adjustments by the native speakers or more proficient interlocutor in social interaction can contribute to second language acquisition. Moreover, Gass (1997) believes that the social interaction in ESL contexts is one of the authentic sources of language input which can help language learners acquire the language in informal settings. In our observation, she also was still not adept in speaking the Korean language as assessed by a Korean native speaker. The reason maybe because in the context where she used the language, there are a few opportunities for contact with native speakers similar in the study of D'Anglejan (1978). In the study of D'Anglejan (1978), he reported that Canadian civil servants freed 
from their jobs for a year to improve their second language did not mostly become fluent in the second language despite strong motivation to learn. He suggested that one reason for this was the absence of any opportunities for contact with native speakers. In addition, the available evidence in the field of second language acquisition research suggests that natural settings are likely to develop oral fluency and pragmatic ability whereas educational settings lead to higher levels of grammatical knowledge (Ellis, 2008).

\subsection{Techniques used to Learn Korean Easily}

Second and foreign language learning strategies can be defined as "any set of operations, steps, plans, routines used by the learner to facilitate the obtaining, storage, retrieval, and use of information" (Wenden\& Rubin, 1987). In learning the Korean language, the participant disclosed that she prefers listening and writing because the Korean language as she noticed that the language is by sound. This affirms to Schimdt's $(1990,1994,2001)$ Noticing Hypothesis. The hypothesis avers that attention to input is a conscious process and that learners 'notice' or register the formal features of a language input. Listening and writing are also include of Oxford's Taxonomy of Strategies. It is part of cognitive strategies by formally practicing with sounds and writing systems of a language. She noticed that Korean language has a different word order so she preferred writing. Indeed, the basic structure of Korean is based on SOV (subject-object-verb) order, while English follows the SVO (subject-verb-object) order (Lee, 2011). She also said that she prefers writing because some letters are spelled and pronounce differently. This is accurate as the initial sounds (consonants) of the Korean alphabet are made up of 14 letters. These 14 are made up from 5 basic forms. When they are translated into English then some of the forms have 2 sounds. For example the kiyok (a Korean consonant) has a sound that is sometimes ' $\mathrm{g}$ ', sometimes ' $\mathrm{k}$ ' (Lee, 2011).

When asked what strategy is the most helpful for her, she identified that it is writing and hearing because it helped her know the difference between pronunciation and meaning. In fact, she keeps a notebook where he wrote the lessons from the instructional videos she saw. The researchers was able to access her notebook and there they observed that she wrote the Korean characters of expressions and its corresponding English translation. She wrote the important content of 100 episodes. In her notebook, she highlighted the title of each episode. This is realization of Oxford's (1990) cognitive strategy of creating structures for input and output by taking down notes, summarizing and highlighting.

Meanwhile she also divulged that studying every dawn and watching Korean dramas are what really helped her learn the language. Studying every dawn corresponds to Oxford classification of strategies where it falls under the category of metacognitive strategies (Oxford, 1990). Under the metacognitive strategies, the learner arranges and plans his or her learning by setting goals and objectives. She is also able to evaluate her learning by self- monitoring (Oxford, 1990). She further revealed that she studied every lesson and at the same time watched Korean drama in order to learn the language. She said if there is something she cannot understand in the drama she 'catches' its meaning. It accords with Oxford's compensation strategies of intelligent guessing by using linguistic cues or other cues. Moreover, she divulged that listening to Korean pop songs have also helped her. She also added that she learned and studied their alphabet first before the meaning of the word because for her, if one will learn the Korean alphabet first, he or she will learn fast and construct words. Moreover, she divulged that Korean movies with subtitles helped her until she can understand watching Korean dramas without subtitles anymore. This supports the study of Pemberton, Fallahkhair, and Masthoff (2004) which utilized the constructionist approach through the use of subtitle which provided comprehensible input. In the study, the participants were given a language learning version of subtitles that provided extra language support, which could help language learners to understand more from their viewing.

\subsection{Difficulties Experienced in Learning Korean Language}

A special characteristic of the Korean language is its honorific system or speech protocol. The way to address someone depends on the speaker's relationship to the person being addressed and the level of formality. For non-native speakers, the proper usage of this speech protocol is one of the most difficult aspects of the language to master (Lee \& Ramsey, 2000). This was true to the participant as she divulged that she finds their dialects and also the honorific protocol of the Korean language as difficult. This may be a problem of conceptual language transfer (Ellis, 2008) as the concept of having to address every people in corresponding terms for respect according to their age, status or position is not really a feature for the previous languages she learned such as Visaya and English. 
Additionally, she related that it is hard for her to understand difficult words and constructing correct sentences. Her native language didn't affect her but other native speakers would discriminate her because she is learning Korean while she just stayed here in Davao. But she still continued because she considers learning the Korean language as an achievement. Also, to overcome the difficulties she encountered, she just studied hard and repeatedly watch the 130 episodes in YouTube. She watched the lessons over and over. Then she also studied books. When she sees a book in the National Book Store, she buys it. Then at times she also received useful things like Korean map and her friend also send her Korean books written in Korean language with no English translation. Her behaviour is similar to what Gan, Humphreys, and Hamp- Lyons (2004) define as a successful language learner. According to them, a successful language learner is reported to set goals for themselves and determined systematic means to achieve them.

\subsection{Triumphs Experienced in Learning Korean Language}

It is thought that students who are most successful when learning a target language are those who like the people that speak the language, admire the culture and have a desire to become familiar with or even integrate into the society in which the language is used (Falk, 1978). Evidently, Caring's love for the Korean culture had contributed greatly for her to find ways to learn their language. When asked which part of learning the Korean language she enjoyed the most, she answered it is everything including their culture. Korea is her favourite place ever since and when she started to learn using internet she always followed it. Then K-Pop came and she followed the trend.

Meanwhile, she finds their greetings as the easiest to learn because it's very basic and it can be used in making conversations. If you ask something about him/ her (Koreans), it can be used again and again.

She thinks that being able to communicate is one of the advantages of learning the Korean language. She shared that she encountered many Koreans in the city who don't seem to know what they're going to do. When she sees a Korean she gets overwhelmed. She finds it fun, and she will approach them and make friends. This is an attitude exhibited by a successful language learner, according to Ellis (2008). Ellis (2008) asserts that a successful language learner has an interest for communication.

She views that having a second language is the most beneficial thing in learning Korean language. She uses the language in chatting Korean friends in social networking sites. Possibly, the participant is trying to 'invest' in a social identity by frequently visiting social networking sites that creates for her appropriate opportunities to learn the second language.

\section{CONCLUSION AND IMPLICATION FOR PRACTICE}

\subsection{Conclusion}

The participant who is studying Korean language without actual encounter of a native speaker or without the aid of a formal language instructor acquired the language through instructional videos and books. She averred that videos were more effective tools for her to acquire the language because it is already complete. It teaches the sound, spelling and English translation of the Korean words and phrase. This affirms the belief that videos can engage learners and thus, can cause for better retention and learning. Moreover, the investigation revealed that instructional videos were more effective tools to acquire the language compared to books for the case of the participant. Through the tools she used, she was able to comprehend a native Korean speaker and was able to exchange ideas with him. However, the Korean language speaker commented that her pronunciation is still unclear for him. Thus, it can be deduced that the participant had still not developed her communication skills properly due to the scarcity of actual opportunities of verbally using the Korean language.

Additionally, the participant engaged various techniques that helped her in learning the Korean language. The participant was well aware of the strategies she used in order to learn the language more easily. She used metacognitive, cognitive and compensation strategies. She studied every dawn and engaged in other activities like watching Korean dramas and listening to K-pop songs in order to learn the Korean language. Being knowledgeable about where she learns best and being able to plan and arrange her learning by setting goals and objectives is a clear manifestation of metacognitive strategies. She further related that when she did not understand the words from the Korean drama, she tried to infer its meaning. Her endeavor to infer the meaning of the words is exhibits compensation strategy, where one attempts to guess meaning through linguistic cues or other cues. Moreover, she 
wrote the important content of the 100 episodes of the instructional videos she saw and she highlighted some of its parts. This displays cognitive strategy. Therefore, for the independent Korean language learner to learn the Korean language, she employed three major strategies namely, metacognitive, compensation and cognitive strategies.

The investigation also lead to the deduction that although the participant experienced various difficulties in learning the Korean language, she found ways to overcome them. Throughout her endeavor to learn the Korean language, she experienced difficulties in some of its features. She also found it hard to understand difficult words and construct sentences. In addition, she also experienced discrimination from her fellow native speakers because of her attempt to learn the Korean language. However, she related that in order to overcome these difficulties, she studied hard and repeatedly watched the instructional videos. She also ignored the judgments of other people around her and considered learning the Korean language on her own as an achievement.

Her delight in learning the Korean language was also manifested during the investigation. She enjoys everything in learning Korean language including their culture. She also enjoys meeting Korean friends. When she encountered Koreans in the city, she tried to make friends with them. Evidently, these are her primary motivations in learning the Korean language

Learning a second language is definitely not easy, but as long as the learner is thoroughly interested in the language and the culture where it is embedded, success can be viewed in the horizon. Caring's motivation and interest helped her to learn the Korean language and despite the scarcity of actual social interactions using the Korean language, she still had developed a fair knowledge and skill in the language.

\subsection{Implications for Practice}

This findings of this study can be useful to language teachers in improving the experiences of their students in the language in order for them to become motivated to learn the language. When students are motivated, it will likely produce to more successful language learners. This study also implicates the importance of using the target language in actual communication to develop communicative competence which will be a helpful insight to the language teachers.

Lastly, the finding of this study also implicates the academe. As the Korean culture continues to flourish and impact other nations through their entertainment and products, more individuals are becoming interested in learning not only their culture, but as well as their language. The increasing population of this individuals suggests that universities can offer language programs which primarily aims to teach the language and culture of Korea, as well as other nations. This can improve the global competitiveness of universities as they welcome various cultures to be taught and learned in their institutions.

\section{REFERENCES}

Altman, R. (1989). The video connection: Integrating video into language teaching. Boston: Houghton-Mifflin Company.

Ausubel, D. (1968). Educational psychology: A cognitive view. New York: Holt, Rinehart, and Winston.

Chavez, A. (2014). What Asia Can Learn From Philippines About English Education Retrieved January 12, 2015 from http://www.huffingtonpost.com/amy-chavez/what-asia-can-learn- from_b_4572991.html

Crotty, M. (1998). The foundations of social research: Meaning and perspective in the research process. Beverly Hills: Sage.

D’Anglejan (1978). Language learning in and out of classrooms in J. Richards (ed.): Understanding Second and foreign language learning: Issues and approaches. Rowley, Mass: Newbury House

Ellis, R. (1997). SLA research and language teaching. Oxford, England: Oxford University Press.

Ellis, R. (2008). The study of Second language acquisition (Second Ed.). Oxford: Oxford University Press.

Falk, J. (1978). Linguistics and language: A survey of basic concepts and implications (2 $\left.{ }^{\text {nd }} e d.\right)$. NJ: John Wiley and Sons. 
Fenton, E. \& Mazulewicz, J.(2008). Trustworthiness. Retrieved June 13, 2015 from http://www. omnivise.com/research/trustworthiness.htm

Francisco, Q. (2002), "Japanese-Korean consortium to put up plant for used cars in Davao City". Retrieved June 13, 2015 from https://en.wikipedia.org/wiki/Koreans_in_the_Philippines

Gan, Z., Humphreys, G., \& Hamp- Lyons, L. (2004). Understanding successful and unsuccessful EFL students in chinese universities. The modern language learner 88: 229-244.

Gass, S. (1997). Input, interaction, and the second language learner. Mahwah, NJ: Lawrence Elrbaum.

Joiner, E. (1986).Listening in the foreign language. In B. Wing (Ed.), Listening, reading, writing: Analysis and application. Reports of the Northwest Conference on the Teaching of Foreign Languages (pp. 43-70). Middlebury, VT: Northeast Conference

Kitajima, R., \& Lyman-Hager, M. A. (2013).Theory-driven use of digital video in foreign language instruction. CALICO journal, 16(1), 37-48.

Kozmonova, M. (2008).Language learning strategies and their training in a primary english class. Czech Republic: Masaryk University Brno.

Krefting, L. (1991).Rigor in qualitative research: The assessment of trustworthiness. American Journal of Occupational Therapy, 45, 214- 222.

Lee, H. (2011). Heritage Voices: Language - Korean. Retrieved June 12, 2015 from http://www.cal. org/heritage/pdfs/heritage-voice-language- korean.pdf

Lee, L., \& Ramsey, S. R. (2000). The Korean language. Albany, NY: State University of New York Press.

Let's Speak Korean. (2008). Retrieved from http://www.arirang.co.kr/

Lewis, P. (2009). (Ed.) Ethnologue: Languages of the world, Sixteenth edition. Dallas, TX: SIL International Online. (See specifically Languages of Korea, North. http://www.ethnologue.com/ show_country.asp?name=KP; A Language of Korea, South. http://www.ethnologue.com/ show_language.asp? code $=$ kor

Lincoln, Y. \&Guba, E. (1985).Naturalistic inquiry, Beverly Hills: Sage.

Long, M. (1996). The role of the linguistic environment in second language acquisition. In W. C. Ritchie \& T. K. Bhatia (Eds.), Handbook of second language acquisition (pp.413-468). New York: Academic Press.

Merriam, S. (1998).Qualitative research and case study applications in education. San Francisco: Jossey-Bass

Ministry of Foreign Affairs and Trade. (2013). Retrieved June 13, 2015 from https://en.wikipedia. org/wiki/Koreans_in_the_Philippines

O’Maggio-Hadley, A. (1993). Teaching language in context (2nd ed.). Boston: Heinle \& Heinle.

Oxford, R. (1990). Language Learning Strategies:What Every Teacher Should Know.Rowley. Mass: Newbury House.

Pemberton, L., Fallahkhair, S. \& Masthoff, G. (2004).Toward a theoretical framework for informal language learning via interactive television. Paper Presented In Proceedings of IADIS International Conference of Cognition and Exploratory Learning in Digital Age. Lisbon, Portugal.

Perez, A. (2014). KPop fans and stans: A deeper look into the Pinoy Hallyu fandom. Retrieved December 16, 2014 from: http://www.gmanetwork.com/news/story/367076/lifestyle/peoplean devents/kpop-fans-and-stans-a-deeper-look-into-the-pinoy-hallyu-fandom

Robinson, P. (2003). Attention and memory during SLA in C. Doughty and M. Long (eds.): Hand book of Second Language Acquisition. Malden, Mass: Blackwell.

Robson, C. (2011). Real World Research. Retrieved July 3, 2015 from http://as.wiley.com/WileyCDA/ WileyTitle/productCd-EHEP001545.html

San Jose, A. E. (2012). Linguistic Experiences of Adult Dyslexic Learners.UIC Research Journals, 18 (1).

Schmidt, R. (1990). The role of consciousness in second language learning. Applied Linguistics, $11,129-158$. 
Schmidt, R. (1994a). Implicit learning and the cognitive unconscious. In N. Ellis (Ed.), Implicit and explicit learning of languages (pp. 165-209). London: Academic Press.

Schmidt, R. (1994b). Deconstructing consciousness in search of useful definitions for applied linguistics. AILA Review, 11, 11-26.

Schmidt, R. (2001). "Attention." In P. Robinson (Ed.), Cognition and second language instruction (pp. 3-32). Cambridge: Cambridge University Press.

Silverman, D. (2013). Doing qualitative research: A practical handbook. Thousand Oaks: SAGE Publications Limited.

Tomlin, R. \& Villa, V. (1994). Attention in cognitive science and second language acquisition. Studies in Second Language Acquisition, 16, 183- 203.

Van Patten, B. (1996). Input processing and grammar instruction in second language acquisition. Norwood, N.J.: Ablex.

Wenden, A. \& Rubin, J. (1987). Learner strategies in language learning. Englewood Cliffs, N.J.: Prentice Hall. World Bank. (2009).

World development indicators: Total population 2009. Retrieved from http://data.worldbank.org/ indicator/SP.POP.TOTL? cid $=G P D \_1$

White, C. (2008). Language Learning Strategies in Independent Language Learning: An Overview. Clevedon: Multilingual Matters.

Yin, R. (2012).Applications of case study research. Los Angeles: Sage

Zhou, Y. (2014). The Korean Wave (Hallyu). Retrieved January 12, 2015 from http://www.aaanet.org/ sections/seaa/2014/07/the-korean-wave-hallyu/ 